\title{
Amelioration of the Journal
}

\author{
Maddury Jyotsna ${ }^{1}$ \\ ${ }^{1}$ Department of Cardiology, Nizam Institute of Medical Sciences \\ (NIMS), Punjagutta, Hyderabad, Telangana, India
}

Ind J Car Dis Wom:2020;5:87-87

\section{Greetings from IJCDW journal!}

Hoping for the safety of all during the COVID era.

For the explicit purpose of improvement of the journal, we would like to add "Abstract Image" and "Audio" to the original articles. Abstract images not only provide a condensed understanding of the original article but also leave a visual impression, as anything viewed has a greater likelihood of being remembered than something which is heard. The addition of audio to the abstract image would have the effect of conveying the author's impression to the listener directly.

Second, we want to lay special focus on medical undergraduates in order to publish their short-term projects in this journal. It may be ideal to have a separate section for this type of papers in the journal. We want to ensure that at least one original article from the medical undergraduate fraternity will be published in each issue of the journal. To this end, we have also introduced modifications in the editorial board.

Journal aims should be flexible and in accordance with the need of the readers. This journal aims to quench the academic thirst of students and new doctors.
The IJCDW journal has already incorporated clinical and interventional rounds to achieve that aim.

In addition, it is better to have a student's corner and organize clinical pathology discussions. For the student's corner, we collated questions from students who were seeking proper explanations. These questions are answered by eminent, clinically oriented, and experienced professors. If one desires to send a clinical question, they can write an email to the Editor-in-Chief in future. Whenever an interesting case arises, we will publish clinical pathology discussions.

A certain section of experts may not eke out time to express their ideas and present it before the medical fraternity. In order to obtain those valuable opinions of experts and simultaneously benefit our readers, the "Expert's Opinion" section has been introduced. Along with the expert opinions, a summary of that particular clinical condition or image will be discussed.

We welcome all to this improved version of the journal.
Address for correspondence Maddury Jyotsna, MD, DM, FACC, FESC, FICC, Department of Cardiology, Nizam Institute of Medical Sciences (NIMS), Punjagutta, Hyderabad 500082, Telangana, India (e-mail: janaswamyjyostna@gmail.com).
DOI https://doi.org/ 10.1055/s-0040-1713962.

(C2020 Women in Cardiology and Related Sciences
License terms

()(1) $\ominus \circledast$ 